\title{
Do They Know How Happy They Are? On the Value of Self-Rated Happiness of People With a Mental Disorder
}

\author{
Ad Bergsma • Ruut Veenhoven • Margreet ten Have $\cdot$ Ron de Graaf
}

Published online: 31 October 2010

(C) The Author(s) 2010. This article is published with open access at Springerlink.com

\begin{abstract}
Quality of life is often measured using questions about happiness. This method presumes that respondents are able to judge their life. Research suggest that this is typically the case, but this is not to say that everybody can. In that context one may doubt whether people with a mental disorder can judge their life adequately. Happiness can be rejected as a indicator for quality of life for people with mental disorders, because of affective and cognitive distortions. We therefore checked the validity of happiness and satisfaction measures in the context of mental disorders. Psychiatric diagnoses were determined at baseline and at 12 and 36 months follow-up in a representative sample $(N=7,076)$ of the Dutch population, using a full Composite International Diagnostic Interview. Respondents indicated how often they had felt happy during the past month and how satisfied they were with their lives in general. The measurements have a satisfactory concurrent, ecological and predictive validity for people with mental disorders. Though the level of happiness is lower among the people with mental disorders, conditions for happiness and contentment appear to be similar.
\end{abstract}

Keywords Happiness - Mental disorders - Life satisfaction - Quality of life · Validity of happiness measure - Positive mood - Mood disorder · Anxiety disorder . Substance abuse disorder

\section{Introduction}

Utilitarianism is the philosophy of life that is based on the idea that that we should seek the greatest happiness for the greatest number (Bentham 1789-1907). On a societal level this idea is gaining momentum. For example, the indicator Gross National Happiness is used as

\footnotetext{
A. Bergsma $(\bowtie) \cdot$ R. Veenhoven

Faculty of Social Sciences, Erasmus University Rotterdam, POB 1738, 3000 DR Rotterdam, The Netherlands e-mail: bergsma@fsw.eur.nl

M. ten Have · R. de Graaf

Netherlands Institute of Mental Health and Addiction, Utrecht, The Netherlands
} 
a goal for development in Bhutan. In 1971 the former king Jigme Singye Wangchuck famously stated that 'Gross National Happiness is more important than Gross National Product' (Priesner 1999, 28). In the West, the same idea is propagated by noted scholars such as Kahneman et al. (1997) and Layard (2005). The idea is that happiness could be used to guide government decisions and for example to choose between rising inflation and unemployment or between more money and less airport noise (Loewenstein and Ubel 2008).

A corner stone of applied utilitarianism is the idea that we can measure happiness in the general population adequately. Several authors defend the position that happiness measures are valid (e.g. Veenhoven 2009), but there is an aspect in the discussion that has not received adequate attention. For people with mental disorders it is claimed that happiness is not a useful indicator for the quality of life, because their moods tend to reflect altered psychological states and not the objective circumstances of their lives (Katschnig 2006; Katschnig et al. 2006; Atkinson et al. 1997; Gill and Feinstein 1994). For example, the subjective experience of life is more negative in depression than outsiders consider justified (Kay et al. 1964), and the patients themselves agree with the outsiders once they have recovered from the acute episode of their illness (Morgado et al. 1991). Katschnig et al. (2006) state that mood is distorted in mental disorders by psychopathological fallacies of an affective, cognitive and reality distortion nature.

The distortions mentioned can be relevant for survey research, because mental disorders are common in general population (e.g. Baumeister and Härter 2007). In the Dutch sample we used for our study, $41.2 \%$ of the respondents had a lifetime prevalence of at least one DSM-III-R disorder at T0. For the prevalence of mental disorders during the past month the prevalence was $16.5 \%$ (Bijl et al. 1998a).

In addition to this, it has become clear that the severest forms of unhappiness are usually associated with mental disorders. In a Dutch sample $84.6 \%$ of the people who had never or rarely felt happy during the past 4 weeks, had (a history of) a mental disorder (Bergsma et al. in press a). Life time prevalence is mentioned, because psychopathology is associated with the residual functional disability even if a disorder is cured or in remission (Bijl and Ravelli 2000).

In this paper we try to assess how serious the psychopathological fallacies are for survey research on happiness. Are the distortions so serious that people with mental disorders are less able to judge their own levels of happiness and satisfaction? Of the three fallacies mentioned, we think that the affective and cognitive are most relevant for survey research in the general population. Reality distortion (psychosis) is quite rare and it is not very likely that people will be recruited for survey research when psychotic symptoms are florid.

The impact of affective and cognitive fallacies can be assessed by research on the affective and cognitive indicators of quality of life. Happiness is often considered to be an affective evaluation of the quality of life, whereas life satisfaction is an evaluation with a stronger cognitive component (Veenhoven 2009). This leads to three research questions:

1. What is the impact of mental disorders on average happiness and life satisfaction ratings in the general population?

2. Is a single item happiness measure valid in the context of mental disorders? In answering this question we also answer the question how serious the affective distortions are and what makes people with mental disorders happy.

3. Is it possible to detect signs of a cognitive psychopathological fallacy that renders lifesatisfactions measures less useful for people with mental disorders? 


\section{Method}

\subsection{Respondents}

The Netherlands Mental Health Survey and Incidence Study (NEMESIS) is a study on the prevalence, incidence, course and outcome of psychiatric disorders in a representative sample $(N=7,076)$ of the general population aged 18-64 (Bijl et al. 1998b). The study is based on a sample of 90 Dutch municipalities, with the stratification of criteria urban residence and adequate distribution over the 12 Dutch provinces. The second step was to draw a sample of private households from post office registers. The number of households selected in each municipality was determined by its population size. The third step was to choose which individuals to interview.

The selected households were sent a letter of introduction signed by the national minister of public health asking them to take part. Shortly thereafter they were contacted by telephone by the interviewers. Households with no telephone or unlisted numbers $(18 \%)$ were visited in person. In each household, the member with the most recent birthday was selected, on the condition that (s) he was between 18 and 64 years and sufficiently fluent in Dutch to be interviewed. Persons who were not immediately available, due to travel, hospitalization or imprisonment, were contacted later. To establish contact, the interviewers made a minimum of ten phone calls or visits to a given address at different times of the day and week. These procedures were approved by the ethics committee of the Netherlands Institute of Mental Health and Addiction.

In the initial data collection phase, from February through December 1996, 7,076 persons were interviewed. The response rate was $69.7 \%$. The participants in the survey reflected well the Dutch population in terms of gender, civil status and urban residence. The 18-24 age group was underrepresented (Bijl et al. 1998b). All participants in the baseline interview were approached for follow-up. As at T0, if necessary the interviewers made at least ten phone calls or visits at various times of the day and week. Of the 7,076 persons who had taken part at T0, 5,618 were interviewed 12 months later at T1 (response $79.4 \%$ ) and of these 4,796 subjects were interviewed 2 years later at T2 (response $85.4 \%$ ) (De Graaf et al. 2000).

\subsection{Mental Disorder}

The Composite International Diagnostic Interview (CIDI), Version 1.1 (computerized version) (Robins et al. 1989) was used to determine mental disorders. The CIDI is a structured interview that was developed by the World Health Organization (Wittchen et al. 1991) and is based on the Diagnostic Interview Schedule (DIS) and the Present State Examination (PSE). It is designed for use by trained interviewers who are not clinicians. CIDI 1.1 contains two diagnostic programs to compute diagnoses according to the criteria and definitions of either DSM-III-R or ICD-10. The CIDI is now being used worldwide, and WHO field trials have documented acceptable reliability and validity (e.g. Wittchen 1994). The following DSM-III-R diagnoses are recorded in NEMESIS: mood disorders (depression, dysthymia, bipolar disorder), anxiety disorders (panic disorder, agoraphobia, simple phobia, social phobia, generalized anxiety disorder, obsessive-compulsive disorder) psychoactive substance use disorders (alcohol or drug abuse and dependence, including sedatives, hypnotics and anxiolytics), eating disorders, schizophrenia and other nonaffective psychotic disorders. In our analysis we used the 1-month prevalence of disorders. We excluded the people with eating disorders $(N=20)$ and schizophrenia $(N=5)$ from 
our sample, because the number of the people affected were too low to have sufficient statistical power.

\subsection{Happiness}

Happiness was measured using a single question taken from the Short-Form-36 Health Survey (SF-36) (Ware and Sherbourne, 1992) about the frequency of happy moods during the past 4 weeks. The (reversed) scale ranged from $1=$ never felt happy, $2=$ rarely felt happy, $3=$ sometimes felt happy, $4=$ often felt happy, $5=$ usually felt happy, until 6 = always felt happy. Our measurement tried to tap Daniel Kahneman's (2000) notion of 'objective happiness', which is the 'raw' affective experience that underlies the overall evaluation of life, because answers to questions about the subjective evaluation of life as a whole are more vulnerable to distortions.

\subsection{Life-Satisfaction}

Satisfaction was measured with questions starting with: 'how satisfied or dissatisfied are you with your ...' and ended with 'most important activity', 'relationships with friends', 'family life', 'recreation', 'current housing', 'income', and 'life in general'. The (reversed) scale ranged from $1=$ very dissatisfied, $2=$ rather dissatisfied, $3=$ neither satisfied or dissatisfied, $4=$ rather satisfied, $5=$ very satisfied. We also used one items from the Rosenberg Self-esteem Scale (Rosenberg 1965) that asks: 'taking all together I am satisfied with myself'. The reversed scale for this item ranged from $1=$ totally disagree, $2=$ disagree, 3 = agree, $4=$ totally agree. When we present data about life-satisfaction next to data about happiness we transformed the scores and to a six point scale, for ease of comparison. This measurements were used to evaluate the potential cognitive distortions in the context of mental disorders.

\subsection{Socio-Demographic Variables}

We included age, gender, educational attainment, cohabitation status; living with a partner or not, irrespective of children, employment status; in paid employment or not, and degree of urban living (rural = municipalities with fewer than 500 addresses per square kilometer; urban $=$ larger municipalities).

\subsection{Mental Ill-Being}

General Health Questionnaire (GHQ-12) has been developed as a screener for non-psychotic mental disorders in the general population. It provides a general measure of mental ill-being, independent of the specific psychiatric diagnosis (Koeter and Ormel 1991). In our analyses we used the sum score, which indicates the seriousness of mental health problems. The internal reliability of this questionnaire in our research cohort was satisfactory (Cronbach's $\alpha=0.85$ ).

\subsection{Mastery}

Locus of control was assessed with the 5-item Mastery Scale (Rotter 1966), with high scores on mastery corresponding to an internal locus of control. The internal reliability of 
this questionnaire in our research cohort was satisfactory (Cronbach's $\alpha=0.81$ ). This measurement was included in our analyses because it is known that mastery has a high correlation with happiness, and we expected that mental disorders have a negative impact on mastery.

\subsection{Neuroticism}

Neuroticism was assessed with the Groninger Neuroticism Questionnaire containing 14 items (Ormel 1980). The internal reliability of the questionnaire in our research cohort was satisfactory (Cronbach's $\alpha=0.80$ ). A higher score indicates higher levels of neuroticism. Neuroticism is included in our analyses, because personality factors are among the strongest and most predictive factors associated with happiness (Diener et al. 1999).

\subsection{Self-Esteem}

We assessed self-esteem with the 10-item Rosenberg Self-esteem Scale (Rosenberg 1965). A high score indicates high self-esteem (Cronbach $\alpha=0.86$ ). This measurement was included because of the expected correlation with both happiness and mental disorders.

\subsection{Analyses}

Our research questions were addressed using descriptive analyses, with the help of SPSS 16.0. We obtained the correlations between our happiness measures and other variables. In Tables 2, 3, 4, 5 we used kendall's tau_b. When we assessed the validity of our happiness measure for people without mental disorders, we first used the data collected in the World Database of Happiness (Veenhoven 2010) as a comparison. Then we assessed if our happiness measure behaved as could be expected based on existing literature for people without mental disorders and then for people with mental disorders. We assessed the congruent, ecological and predictive validity.

In Tables 1 and 3 our happiness variable was dichotomized in infrequent happy moods $(1,2,3)$ and frequent happy moods (felt at least often happy, 4, 5, 6). When we assessed if the correlations for people with and without mental disorders differed significantly, we used Fischer r-to-z transformations.

\section{Results}

\subsection{Question 1: The Impact of Mental Disorders on Average Happiness and Life Satisfaction}

Average happiness at T0 $(N=7,069)$ in our sample from the general population was 4.77 (SD 1.06) and average life satisfaction $(N=7,075)$ was 5.13 (SD 0.94). As expected happiness and life-satisfaction are lower for people with mental disorders. The average happiness for people with mental disorders $(N=1,135)$ is 4.12 (SD 1.35) and average lifesatisfaction $(N=1,137)$ is 4.55 (SD 1.24). If we excluded people with 1-month mental disorders from our sample, the average happiness and life satisfaction was higher. Average happiness for the general population without mental disorders $(N=5,934)$ is 4.90 (SD $0.95)$ and average life satisfaction for this group $(N=5,938)$ is 5.24 (SD 0.83). 
Table 1 Happiness during the past 4 weeks among people with mental disorders

\begin{tabular}{|c|c|c|c|c|}
\hline $\begin{array}{l}\text { Mental disorder during } \\
\text { previous month }\end{array}$ & $N$ & $\begin{array}{l}\text { Percentage that felt } \\
\text { at least often happy } \\
\text { during the last } \\
4 \text { weeks (CI 95\%) }\end{array}$ & Pure cases $N$ & $\begin{array}{l}\text { Percentage that felt } \\
\text { at least often happy } \\
\text { during the last } \\
4 \text { weeks (CI 95\%) }\end{array}$ \\
\hline No disorder & 5934 & $89.1(88.3-89.9)$ & & \\
\hline Any disorder & 1104 & $66.6(63.8-69.4)$ & 781 & $76.1(73.1-79.0)$ \\
\hline Any mood disorder & 282 & $30(24-35)$ & 102 & $37(28-47)$ \\
\hline Major depression & 185 & $22(16-28)$ & 55 & $29(17-41)$ \\
\hline Bipolar disorder & 42 & $43(27-58)$ & 17 & $53(26-79)$ \\
\hline Dysthymia & 127 & $32(24-41)$ & 30 & $43(25-62)$ \\
\hline Any anxiety disorder & 691 & $66(62-69)$ & 426 & $80(76-84)$ \\
\hline Panic disorder & 103 & $42(32-51)$ & 29 & $79(64-95)$ \\
\hline Agoraphobia & 77 & $62(51-73)$ & 27 & $78(61-95)$ \\
\hline Social phobia & 263 & $60(54-66)$ & 121 & $76(68-84)$ \\
\hline Simple phobia & 399 & $69(65-74)$ & 231 & $84(79-89)$ \\
\hline Generalized anxiety disorder & 54 & $50(36-64)$ & 13 & $54(22-85)$ \\
\hline Obsessive compulsive disorder & 19 & $32(9-55)$ & 5 & $60(0-100)$ \\
\hline Any abuse or dependency & 334 & $76(71-81)$ & 253 & $85(81-90)$ \\
\hline Alcohol abuse & 139 & $90(85-95)$ & 119 & $94(90-98)$ \\
\hline Alcohol dependence & 164 & $69(62-76)$ & 115 & $81(74-88)$ \\
\hline Drug abuse & 14 & $71(44-99)$ & 5 & $80(24-100)$ \\
\hline Drug dependence & 36 & $50(33-67)$ & 14 & $50(20.0-80.0)$ \\
\hline
\end{tabular}

\subsubsection{Discussion}

As expected the exclusion of people with mental disorders from our sample, led to higher average happiness and life-satisfaction. The difference was modest. In percentages, happiness was raised by 2,7 and life-satisfaction by $2,1 \%$. This may indicate that people with mental disorders do not disturb survey ratings of happiness and life-satisfaction, but we think that it is too early for such a conclusion.

The average happiness and life-satisfaction of people with mental disorders is not very low. This could mean that the affective and cognitive psychopathological fallacies may not only make people dissatisfied and unhappy without an objective base in the circumstances of life. It also could be that some people with mental disorders report unwarranted levels of happiness and satisfaction that may be the result from lacking insight in their own situation. Again this could seriously hamper the reliability of survey results, so we checked the validity of our happiness and life-satisfaction measure.

\subsection{Question 2: The Validity of Happiness Measures in the Context of Mental Disorders}

Mental disorders are not synonymous with deep unhappiness. Table 1 shows the percentages of people with different mental disorders at T0 that report to have been happy at least often. Notably people with pure anxiety disorders and substance abuse disorders report frequent happy moods. 
A first indication for the validity of our happiness measure is that happiness reports reflect the clinical characteristics of the disorder. People report lower happiness if they have more serious conditions. For example, people abusing substances or alcohol are happier than people being dependent. In the anxiety disorders, the simple phobia is associated with most frequent happy moods and the obsessive compulsive and generalized anxiety disorders are associated with least frequent happy moods. In the mood disorders, dysthymia is associated with more frequent happy moods than a major depressive disorder. Table 1 also shows that people with pure disorders are happier than people with more than one disorder.

One possible explanation for the frequent happy moods of people with mental disorders is that they have lowered their standards for happiness, so that they might describe their mood as happy, although in reality their moods are low. If this were the case, we would expect that people with more chronic conditions, would show clearer signs of adaptation to low moods and report higher levels of happiness. We compared people with any mental disorder during $\mathrm{T} 2$ according to their history during earlier measurements at T0 and $\mathrm{T} 1$. In this sample, the people without mental disorders at T0 or T1 $(N=157)$ reported an average happiness of 4.1 (95\% CI. 3.9-4.3). The people with any mental disorder during T0 or T1 $(N=125)$ reported an average happiness of 3, 7 (95\% CI. 3.5-4.0), and the people with any mental during both T0 and T1 $(N=102)$ reported 3.6 (95\% CI. 3.3-3.9). Happiness was lower for people who were diagnosed more often as having a mental disorder, i.e. those who had a more chronic condition. This seems to indicate that more frequent happiness is not a sign of lowering standards and adaptation, but an indication that the condition is less serious.

\subsection{Congruent Validity}

We assessed at T0 if our happiness measure is correlated with other measurements in the way that could be expected on the basis of existing literature. We first focused on people without mental disorders. This yielded the expected results (Table 2). For example, people who are satisfied with life and family relationships, who feel vivacious and relaxed, and do not suffer from loneliness report higher levels of happiness. The same is true for people with high levels of self-esteem and mastery, and low levels of mental ill-being and neuroticism.

The congruent validity of our happiness measure seemed valid for people without mental disorders. When we repeated the procedure with people with mental disorders, we got essentially the same results, with one meaningful difference (Table 3). The correlations are higher for people with mental disorders than for people without mental disorders. The difference between the correlations coefficients was significant.

We tested if the difference was an artifact of the skewness of the distribution of our happiness measure. Therefore we created a new happiness variable that was corrected for the (mild) negative skewed distribution $(-1.11)$, but this did not result in a significant moderation of the differences in the correlations between the groups with and without mental disorders.

\subsection{Ecological Validity}

The existing literature indicates that objective circumstances explain a small part of the variation in happiness, and this is what we noticed in our sample at T0 as well. Factors such as gender, household income, level of education are very modestly correlated with 
Table 2 Correlates of happiness among people with and without mental disorders
$* P<0.05$ (two tailed)

** $P<0.01$ (two tailed)

\begin{tabular}{llll}
\hline Characteristic & $\begin{array}{l}\text { No disorder } \\
\text { previous } \\
\text { month }\end{array}$ & $\begin{array}{l}\text { Any disorder } \\
\text { previous } \\
\text { month }\end{array}$ & $\begin{array}{l}\text { Difference } \\
\text { in correlations }\end{array}$ \\
& & \\
\hline
\end{tabular}

\begin{tabular}{lrrl}
\hline Single items & & & \\
Life satisfaction & $0.39 * *$ & $0.53^{* *}$ & $0.14^{* *}$ \\
$\begin{array}{l}\text { Satisfaction with } \\
\text { family life }\end{array}$ & $0.36^{* *}$ & $0.41^{* *}$ & $0.06^{*}$ \\
$\begin{array}{l}\text { Felt did something } \\
\text { meaningful lately? }\end{array}$ & $0.13^{* *}$ & $0.27^{* *}$ & $0.14^{* *}$ \\
Felt lonely & $-0.19^{* *}$ & $-0.33^{* *}$ & $0.14 * *$ \\
Felt vivacious & $0.40^{* *}$ & $0.48^{* *}$ & $0.08^{* *}$ \\
Felt calm, relaxed & $0.40^{* *}$ & $0.47^{* *}$ & $0.07 * *$ \\
Questionnaires & & & \\
Self-esteem & $0.272^{* *}$ & $0.345^{* *}$ & $0.07 *$ \\
Neuroticism & $-0.31^{* *}$ & $-0.46^{* *}$ & $0.15^{* *}$ \\
Mastery & $0.26^{* *}$ & $0.39^{* *}$ & $0.13^{* *}$ \\
Mental ill-being & $-0.30^{* *}$ & $-0.45^{* *}$ & $0.15^{* *}$ \\
\hline
\end{tabular}

happiness. The objective circumstances explain little variance in happiness. This is true for people with and without mental disorders. The differences between the two groups are sometimes significant, but so small that we did not try to interpret the difference.

To further assess the ecological validity of our happiness measure for people with mental disorders, we focused on indicators for the seriousness of one's disorder. Happier respondents with mental disorders had less days absent from work because of the mental disorder (Kendall tau-b $=-0.25, P<0.01$ ), used less sleeping pills (Kendall tau- $\mathrm{b}=-$ $0.17, P<0.01$ ), less anti-depressives (Kendall tau-b $=-0.15, P<0.01$ ), less tranquillizers (Kendall tau-b $=-0.16, P<0.01$ ), and less pain killers (Kendall tau-b $=-0.10$, $P<0.01)$.

\subsection{Predictive Validity}

Frequent happy moods at T0 reduces the chances of having a mental disorder 1 year later at T1. This was true for people with mental disorders at T0 (Kendall tau-b $=0.19$, $P<0.01$ ) and for people without mental disorders at T0 (Kendall tau-b $=0.07, P<0.01$ ). The difference in the correlations was again significant $(P<0.01)$. Table 3 shows the chances of having a mental disorder at T1 for different groups.

Table 3 Course of any mental disorder among people with and without frequent feelings of happiness at baseline (T0)

\begin{tabular}{lll}
\hline & No disorder at T1 & Any disorder at T1 \\
& $N=4756(\%)$ & $836(\%)$ \\
\hline No frequent happy moods at T0 & 89.3 & 57.7 \\
At least often happy at T0 & 96.2 & 75.4 \\
\hline
\end{tabular}




\subsubsection{Discussion}

In this part of the study we checked if affective psychopathological fallacies that comes with mental disorders render happiness ratings less valid. We can reject this idea on four grounds. The first is that happiness reflects clinical characteristics of mental disorders. People diagnosed as having a mental disorder report less happiness than people without, and more serious disorders are associated with less happiness. Other indicators of the severity of mental disorders such as the chronic nature of the disorder and the existence of comorbid mental disorder are also negatively correlated with happy moods.

The congruent validity, ecological and predictive validity of happiness is satisfactory in the context of mental disorders. The same psychological factors that are associated with happiness in the general population are correlated with happiness for people with mental disorders. More frequent happy moods predict the recovery from mental disorders 1 year later. Sociodemographic factors that are largely uncorrelated with happiness for people without mental disorders, are also not, or very modestly, correlated with happiness for people with mental disorders.

There was however one meaningful difference between the people with and without mental disorders. Psychological factors show a significantly higher correlation with happiness for people with mental disorders than for people without mental disorders. This suggests that people with mental disorders have a higher sensitivity for psychological problems that can harm their moods.

Among people with mental disorders, those with high self-esteem, who feel in control of their lives, who feel vivacious, relaxed and have high emotional stability (low neuroticism), who are satisfied with life and family relationships, and have less symptoms of psychological ill-health are most likely to experience frequent happy moods. The level of happiness is lowered in mental disorders, but conditions of happiness are the same for people with and without mental disorders.

\subsection{Question 3: The Validity of Life-Satisfaction Measures in the Context of Mental Disorders}

In the introduction we mentioned that research has shown that the subjective experience of life is more negative in mental disorders than outsiders consider justified. The direct way to check if this is true is showing that the relationships between life satisfaction and the objective circumstances of life are significant for people without mental disorders, and more modest or not significant for people with disorders. The problem with this approach is that life-satisfaction of people without disorders is very modestly correlated with actual circumstances. The same is true for people with mental disorders (Table 4). The exceptions are pay status of a job and gender. In general, we can conclude that the variance in lifesatisfaction in The Netherlands cannot be explained with the help of the objective circumstances, and this as true for people with as for people without mental disorders.

Another test of the validity of the life-satisfaction measure is to assess how it correlates with satisfactions with life domains. A cognitive psychopathological fallacy could disturb the coherence of ratings. However, people with and without mental disorders showed the same coherence in judging their life-satisfaction (Table 5). There was no difference in the amount of variance explained, but for the different groups different aspects weighted more. For people with mental disorders the correlation with general life-satisfaction was higher for satisfaction with themselves and with recreation. For people without mental disorders the correlation was higher for satisfaction with income and with current housing. 
Table 4 Correlates of general life-satisfaction and sociodemographic characteristics of people with and without mental disorders

\begin{tabular}{lccc}
\hline Characteristic & $\begin{array}{l}\text { No disorder } \\
\text { previous month }\end{array}$ & $\begin{array}{l}\text { Any disorder } \\
\text { previous month }\end{array}$ & $\begin{array}{c}\text { Difference in } \\
\text { correlations }\end{array}$ \\
\hline Gender (male $=0$, female $=1)$ & $0.09^{* *}$ & 0.00 & $-0.09^{* *}$ \\
Age & -0.02 & $-0.07^{*}$ & 0.05 \\
Urbanization & $0.06^{* *}$ & $0.07^{*}$ & 0.01 \\
Living alone or with others & $0.18^{* *}$ & $0.20^{* *}$ & 0.02 \\
Household income & $0.14^{* *}$ & $0.19^{* *}$ & 0.05 \\
Paid job & 0.02 & $0.11^{* *}$ & $0.09 * *$ \\
Level of education & -0.03 & -0.06 & 0.03 \\
Had sex during past year & $0.13^{* *}$ & $0.15^{* *}$ & 0.02 \\
\hline
\end{tabular}

$* P<0.05$ (two tailed)

$* * P<0.01$ (two tailed)

Table 5 Correlates of general life-satisfaction with satisfaction on different domains of life among people with and without mental disorders

\begin{tabular}{lllc}
\hline Satisfaction with & $\begin{array}{l}\text { No disorder } \\
\text { previous month }\end{array}$ & $\begin{array}{l}\text { Any disorder } \\
\text { previous month }\end{array}$ & $\begin{array}{l}\text { Difference in } \\
\text { correlations }\end{array}$ \\
\hline Family life & $0.45^{* *}$ & $0.47^{* *}$ & 0.02 \\
Most important activity & $0.37^{* *}$ & $0.40^{* *}$ & 0.03 \\
Relationships with friends & $0.36^{* *}$ & $0.34^{* *}$ & -0.02 \\
Recreation & $0.33^{* *}$ & $0.40^{* *}$ & $0.07 *$ \\
Income & $0.33^{* *}$ & $0.26^{* *}$ & $-0.07^{*}$ \\
Myself & $0.29^{* *}$ & $0.43^{* *}$ & $0.14^{* *}$ \\
Current housing & $0.26^{* *}$ & $0.16^{* *}$ & -0.10 \\
\hline
\end{tabular}

$* P<0.05$ (two tailed)

** $P<0.01$ (two tailed)

The satisfaction with life of people with mental disorder do not show a clear sign of cognitive fallacies. This results runs counter to the message of Katschnig that self-rated happiness and satisfaction is the result of psychopathology. This might be due to the fact that Katschnig reports from clinical samples and we from the general population. We therefore specifically looked at the life-satisfaction of the people with lowest levels of happiness. For people that report to have been happy never, seldom of sometimes during the past 4 weeks, we do get a significant difference between people with and without a disorder if we calculate the correlation (kendall tau-b) between happiness and life satisfaction. For unhappy people without a disorder, the association between life-satisfaction and happiness is $0.14(P<0.01)$, whereas the association between life-satisfaction and happiness is $0.45(P<0.01)$ for unhappy people with mental disorders. The difference is significant $(P<0.01)$.

\subsubsection{Discussion}

The coherence of satisfaction with life domains and general life satisfaction for people with and without mental disorders indicate that measures of life-satisfaction are useful for 
people. The cognitive psychopathological fallacies for people with mental disorders are not so strong that the life-satisfaction measures are incoherent. The almost absent correlation between life-satisfaction and objective life circumstances for people with and without mental disorders, also indicate that there are no good reasons to distrust the self-reports of people with mental disorders.

There is however ground for the observations mentioned in the introduction. People with mental disorders that are unhappy, are more dissatisfied with life than unhappy people without disorders. We think that this indicates that people with mental disorders are less able to distance themselves from their dominant moods. When they feel low, they are more dissatisfied with life, whereas unhappy people without disorders are able to correct their judgements for this affective bias. This is an importance difference, that is clinically significant, but we do not believe that we can conclude that we should regard this as a cognitive fallacy that renders life-satisfaction measures useless.

\section{General discussion}

\subsection{Happiness and Life Satisfaction Ratings in Surveys can be Used For Everyone}

The fact that mental disorders are common in the general population does not rule out the possibility to use survey question about happiness or life-satisfaction. The existence of mental disorders has a very modest impact on average happiness ratings in the general population, and we could find no indication that affective of cognitive psychopathological fallacies make the measures less trustworthy.

\subsection{Happiness Measures are Valid for People with Mental Disorders}

Our single item happiness rating shows satisfactory congruent, ecological and predictive validity for people with and without mental disorders. The same psychological factors that are associated with happiness for people without mental disorders, are associated with happiness for people with mental disorders. The conditions of happiness are the same for people with and without mental disorders, but the conditions are relatively more important for people with disorders.

\subsection{Life-Satisfaction is a Useful Indicator for Quality of Life for People with Mental Disorders}

We could not find signs that a cognitive psychopathological fallacy rendered the lifesatisfaction ratings less useful for people with mental disorders compared to those without disorders.

\subsection{More Sensitivity}

We interpret the fact that happiness of people with mental disorders is more sensitive to psychological factors, as a logical consequence of the diathesis-stress theory of mental disorders (e.g. Monroe and Simons 1991). The theory states people can have a specific vulnerability to develop a disorder and that the disorders occurs is stressors exceed the coping mechanisms. 
People without mental disorders are less sensitive, and psychological factors such as less self-esteem, less mastery and more neuroticism, have a smaller negative influence on their happiness and life-satisfaction ratings, compared to people with disorders. People with mental disorders experience more stress and every added problem therefore has a stronger impact. Unhappy people with low moods are more likely to be satisfied with life, probably because they are better able to correct their cognitive judgment for current affective influences.

\subsection{Practical Implications}

Our findings have two important practical implications. The first is that we have found no reason to exclude happiness or life-satisfaction ratings of people with mental disorders in surveys in the general population. The happiness ratings of people with mental disorders in the general population are as valid as those of people without disorders.

The second implication is for positive psychology that seeks to improve positive psychological functioning. The natural target group for positive psychology interventions (Seligman and Csikszentmihalyi 2000) seem to be the people with mental disorders. They are least happy and show most room for improvement (Bergsma et al. in press b), and they might be most sensitive for enhancement of positive psychological factors. On the basis of our data we expect that interventions that raise self-esteem and mastery, and lower neuroticism and psychological ill-being, will give a higher return in gained happiness for people with mental disorders, because of the higher association of these factors with happiness. Helping people to find paid employment also can have a higher impact on happiness for the people with mental disorders.

We therefore agree with a pamphlet of the London School of Economics (2006) with the title The depression report; A New Deal for Depression and Anxiety Disorders. From an utilitarian point of view, the authors came to the conclusion that we should train an army of psychotherapists to raise happiness.

\subsection{Limitations}

We used a measure of happiness that directly referred to dominant moods. In the literature about happiness another definition is more common. Veenhoven (1984, 22-24) defines happiness as "the degree to which an individual judges the overall quality of his life-as-awhole favorably". In our data we did not have any data to study this concept of happiness. This form of happiness is considered to be built up by affects and thoughts, or moods and contentment with (domains of) life. In our study we were able to assess the validity of the components of overall happiness, but we did not study how people with and without mental disorders combined the two sources of information to judge their own overall happiness. This question warrants further study.

A second limitation is that we analysed the answers of people with mental disorders in a general survey. People with the most serious mental disorders, such as schizophrenia, are underrepresented in our sample. For the most severe forms of mental disorders the psychopathological fallacies mentioned by Katschnig are probably more important. Our results are relevant for general surveys, but not necessarily for clinical studies on quality of life with people with most severe forms of psychopathology. 
Open Access This article is distributed under the terms of the Creative Commons Attribution Noncommercial License which permits any noncommercial use, distribution, and reproduction in any medium, provided the original author(s) and source are credited.

\section{References}

Atkinson, M., Zibin, S. H., \& Chuang, H. (1997). Characterizing quality of life among patients with chronic mental illness: A critical examination of the self-report methodology. American Journal of Psychiatry, $154,99-105$.

Baumeister, H., \& Härter, M. (2007). Prevalence of mental disorders based on general population surveys. Social Psychiatry and Psychiatric Epidemiology, 42, 537-546.

Bentham, J. (1907-1789). Introduction to the Principles of Morals and Legislation. Oxford: Clarendon Press.

Bergsma, A., Ten Have, M., Veenhoven, R., \& De Graaf, R. Most people with mental disorders are happy; A 3-year follow-up in the Dutch general population. The Journal of Positive Psychology (in press).

Bergsma, A., Veenhoven, R., Ten Have, M., \& De Graaf, R. Happy life expectancy associated with various mental disorders. Netherlands Journal of Psychology (in press).

Bijl, R. V., \& Ravelli, A. (2000). Current and residual functional disability associated with psychopathology: Findings from the Netherlands Mental Health Survey and Incidence Study (NEMESIS). Psychological Medicine, 30, 657-668.

Bijl, R. V., Ravelli, A., \& Van Zessen, G. (1998b). Prevalence of psychiatric disorder in the general population: Results of the Netherlands Mental Health Survey and Incidence Study (NEMESIS). Social Psychiatry Psychiatric Epidemiology, 33, 587-595.

Bijl, R. V., Van Zessen, G., Ravelli, A., De Rijk, C., \& Langendoen, Y. (1998a). The Netherlands Mental Health Survey and Incidence Study (NEMESIS): Objectives and design. Social Psychiatry Psychiatric Epidemiology, 33, 581-586.

De Graaf, R., Bijl, R. V., Smit, F., Ravelli, A., \& Vollebergh, W. A. M. (2000). Psychiatric and Sociodemographic Predictors of Attrition in a Longitudinal Study The Netherlands Mental Health Survey and Incidence Study (NEMESIS). American Journal of Epidemiology, 152, 1039-1047.

Diener, E., Eunkook, M. S., Lucas, R. E., \& Smith, H. L. (1999). Subjective well-being: Three decades of progress. Psychological Bulletin, 125, 276-301.

Gill, T. M., \& Feinstein, A. R. (1994). A critical appraisal of the quality of quality-of-life measurements. JAMA, 272, 619-626.

Kahneman, D. (2000). Experienced utility and objective happiness: A moment based approach. In D. Kahneman \& A. Tverski (Eds.), Choices, values and frames. New York: Cambridge University Press.

Kahneman, D., Wakker, P., \& Sarin, R. (1997). Back to Bentham: Explorations of experienced utility. Quarterly Journal of Economics, 112, 375-405.

Katschnig, H. (2006). Quality of life in mental disorders: Challenges for research and clinical practice. World Psychiatry, 5(3), 139-145.

Katschnig, H., Freeman, H., \& Satorius, N. (Eds.). (2006). Quality of life in mental disorders (2nd ed.). Chichester: John Wiley \& Sons.

Kay, D. W. K., Beamisch, P., \& Roth, M. (1964). Old age mental disorders in Newcastle-upon-Tyne, II; A study of possible social and medical causes. British Journal of Psychiatry, 110, 668-682.

Koeter, M. W. J., \& Ormel, J. (1991). Handleiding bij de general health questionnaire. Lisse: Swets en Zeitlinger.

Layard, R. (2005). Happiness: Lessons of a new science. New York: Penguin.

Loewenstein, G., \& Ubel, P. A. (2008). Hedonic adaptation and the role of decision and experience utility in public policy. Journal of Public Economics, 92, 1795-1810.

London School of Economics. (2006). The depression report; A new deal for depression and anxiety disorders. London: The Centre for Economic Performance's Mental Health Policy group.

Monroe, S. M., \& Simons, A. D. (1991). Diathesis-stress theories in the context of life stress research: Implications for the depressive disorders. Psychological Bulletin, 110(3), 406-425.

Morgado, A., Smith, M., Lecrubier, Y., \& Widlöcher, D. (1991). Depressed subjects unwittingly overreport poor social adjustment which they reappraise when recovered. The Journal of Nervous and Mental Disease, 179(10), 614-619.

Ormel, H. (1980). Moeite met leven of een moeilijk leven. Groningen: University Groningen. 
Priesner, S. (1999) Gross national happiness-Bhutan's vision of development and its challenges. Published in 'Gross National Happiness, Discussion papers, The Centre for Bhutan Studies (pp. 24-52). Thimphu, Bhutan.

Robins, L. N., Wing, J., Wittchen, H. U., Helzer, J. E., Babor, T. F., Burke, J. D. et al. (1989). The Composite International Diagnostic Interview: An epidemilogic instrument suitable for use in conjunction with different diagnostic systems and in different cultures. Achives of General Psychiatry, 45, 1069-1077.

Rosenberg, M. (1965). The measurement of self-esteem. Princeton NJ: Princeton University Press.

Rotter, J. B. (1966). Generalized expectancies for internal versus external control of reinforcement. Psychological Monographs: General and Applied, 80(1), 1-28.

Seligman, M. E. P., \& Csikszentmihalyi, M. (2000). Positive psychology: An introduction. American Psychologist, 55(1), 5-14.

Veenhoven, R. (1984). Conditions of happiness. Dordrecht/Boston: Kluwer Academic.

Veenhoven, R. (2009). How do we assess how happy we are? In A. Dutt \& B. Radcliff (Eds.), Happiness, economics and politics (pp. 45-69). Northampton: Edward Elger.

Veenhoven, R. (2010). World Database of Happinesss. Erasmus University Rotterdam. Available at: http://worlddatabaseofhappiness.eur.nl.

Ware, J. E., Jr., \& Sherbourne, C. D. (1992). The MOS 36-item short-form health survey (SF-36) I. Conceptual framework and item selection. Medical Care, 30(6), 473-483.

Wittchen, H.-U. (1994). Reliability and validity studies of the WHO Composite International Diagnostic Interview (CIDI). Journal of Psychiatric Research, 28, 57-84.

Wittchen, H-U., Robins, L. N., Cottler, L. B., Sartorius, N., et al. (1991). Cross-cultural feasibility, reliability and sources of variance in the Composite International Diagnostic Interview (CIDI). British Journal of Psychiatry, 159, 645-653. 